$\xi=-1$

\title{
Multiobjective Optimization of Injection Moulding Process Parameters on Mechanical Properties Using Taguchi Method and Grey Relational Analysis
}

\author{
Mohd Amran Md Ali ${ }^{1,2 *}$, Noorfa Idayu ${ }^{1}$, Raja Izamshah ${ }^{1,2}$, Mohd Shahir Kasim ${ }^{1,2}$, Mohd Shukor Salleh ${ }^{1,2}$, Sivarao ${ }^{1,2}$ \\ ${ }^{1}$ Faculty of Manufacturing Engineering, Universiti Teknikal Malaysia Melaka (UTeM), 76100 Durian Tunggal, Melaka, Malaysia \\ ${ }^{2}$ Advanced Manufacturing Centre (AMC), Faculty of Manufacturing Engineering, Universiti Teknikal Malaysia Melaka (UTeM), 76100 \\ Durian Tunggal, Melaka, Malaysia \\ *Corresponding author E-mail: mohdamran@utem.edu.my
}

\begin{abstract}
This study presents an optimization of injection moulding parameters on mechanical properties of plastic part using Taguchi method and Grey Relational Analysis (GRA) approach. The orthogonal array with L9 was used as the experimental design. Grey relational analysis for ultimate tensile strength, modulus and percentage of elongation from the Taguchi method can convert optimization of the multiple performance characteristics into optimization of a single performance characteristic called the grey relational grade (GRG). It is found that mould temperature of $62^{\circ} \mathrm{C}$, melt temperature of $280^{\circ} \mathrm{C}$, injection time of $0.70 \mathrm{~s}$ and cooling time $15.4 \mathrm{~s}$ are found as the optimum process setting. Furthermore, ANOVA result shows that the cooling time is the most influenced factor that affects the mechanical properties of plastic part followed by mould temperature and melt temperature.
\end{abstract}

Keywords: Injection moulding, Multiobjective optimization, Taguchi method, Grey relational analysis, Mechanical properties

\section{Introduction}

Polypropylene (PP) is considered as a popular thermoplastic material which becomes one of the most widely used plastic material and produced in large quantities due to its used in many applications. The application of PP has a wide coverage in automobile industry, household equipment, electrical devices, packaging and many others [1-3]. Plastic injection moulding is the most common manufacturing method to manufacture a desired plastic part with specific shape and size. In addition, the process parameters of injection moulding affect the quality and performance of the moulded product. The optimization of process parameters such as melt temperature, mould temperature, injection and holding pressure, holding time, cooling time and injection speed is needed to produce plastic products that have a better performance in term of mechanical properties [4].

There have been several studies to study the effect of process parameters on mechanical properties of plastic part. Mirvar et al. [5] found that the process parameters such as holding pressure time is the most influenced factor that affect the tensile strength followed by cooling time and holding pressure. In 2013, Mehat et al. [6] studied the effect of process parameters such as melt temperature, packing pressure, packing time and cooling time on ultimate strength and elongation at break of plastic gear. They found that the changes in the process parameters have contributed the variation of result in the mechanical properties of the plastic part.

One of the common optimization methods is Taguchi method that has been implemented by many researchers to optimize their desired objective and output. [7-10]. Taguchi method uses orthogonal array, signal-to-noise ratio as well as analysis of variance
(ANOVA) to optimize the process parameters and the advantage of this method is time and cost can be reduced due to its orthogonal array method. However, optimization using Taguchi method can only optimize a single objective.

Some researchers have approached a multiobjective method called Taguchi with Grey Relational Analysis method to get the best combination of process parameters of multiple characteristic performances. [11-13]. Therefore, the aim of this paper to optimize injection moulding parameters on mechanical properties such as ultimate tensile strength, modulus and percentage of elongation of plastic part using Taguchi method and Grey Relational Analysis approach.

\section{Methodology}

\subsection{Materials and Experimental Method}

The plastic materials, Polypropylene (PP) were supplied by Lotte Chemical Titan (M) Sdn, Bhd. with properties of melt flow rate, $4.0 \mathrm{~g} / 10 \mathrm{~min}$ and density of $0.9 \mathrm{~g} / \mathrm{cm} 3$. The injection moulding used for the experiment was Allrounder $370 \mathrm{H} \mathrm{600-170} \mathrm{Hybrid}$ machine (ARBURG). Dumbbell specimen for tensile test is in accordance with ASTM D638 and tensile tests were performed at room temperature in an Instron Universal Testing Machine with a cross-head speed of $50 \mathrm{~mm} / \mathrm{min}$.

\subsection{Design of Experiment Using Taguchi Method}

Four parameters with three levels such as mould temperature, melt temperature, injection time and cooling time [14] were considered 
as process parameters for this experiment. An orthogonal table of L9 was established as shown in Table 1.

Table 1: Process parameters and their levels

\begin{tabular}{|c|c|c|c|}
\hline \multirow{2}{*}{ Process Parameters } & \multicolumn{3}{|c|}{ Level } \\
\cline { 2 - 4 } & Low & Medium & High \\
\hline $\begin{array}{c}\text { Mould Temperature, } \\
\text { MoT }\left({ }^{\circ} \mathrm{C}\right)\end{array}$ & 50 & 56 & 62 \\
\hline Melt Temperature, MeT $\left({ }^{\circ} \mathrm{C}\right)$ & 250 & 280 & 310 \\
\hline $\begin{array}{c}\text { Injection Time, } \\
\text { IT (s) }\end{array}$ & 0.63 & 0.70 & 0.77 \\
\hline $\begin{array}{c}\text { Cooling Time, } \\
\text { CT (s) }\end{array}$ & 12.6 & 14.0 & 15.4 \\
\hline
\end{tabular}

\subsection{Grey Relational Analysis (GRA)}

In grey relational analysis (GRA), the data from experimental result is pre-processing to normalize the random grey data with varied units and the original sequences is converted into a comparable sequence between the values of zero to one [15]. The following equation shows the normalization method depends on the characteristic of the particular attributes.

Equation (1) is used for the-larger-the-better characteristic,

$x_{i}(k)=\frac{x_{i}^{O}(k)-\min x_{i}^{0}(k)}{\max x_{i}^{O}(k)-\min x_{i}^{O}(k)}$

Equation (2) is used for the-lower-the-better characteristic,

$x_{i}(k)=\frac{\max x_{i}^{0}(k)-x_{i}^{0}(k)}{\max x_{i}^{O}(k)-\min x_{i}^{0}(k)}$

Equation (3) is used for closer to the desired value that has thenominal-the-better characteristic,

$x_{i}(k)=1-\frac{\llbracket x_{i}^{0}(k)-x_{i}^{0} \rrbracket}{\max x_{i}^{0}(k)-x_{i}^{0}}$

Where, $i=1, \ldots, \mathrm{m} ; k=1, \ldots, \mathrm{n} . m$ is the number of experimental data set, $n$ is the number of responses. $x_{i}^{O}(k)$ denotes the original sequence, $x_{i}(k)$ is known as comparability sequence which is had after pre-processing, max $x_{i}^{\circ}(k)$ and $\min x_{i}^{0}(k)$ are the largest and smallest value of $x_{i}^{O}(k)$ respectively; $x_{i}^{0}$ implies the desired value for $x_{i}^{0}(k)$.

After pre-processing or normalization step, the grey relational coefficient is needed for $k^{\text {th }}$ response characteristic for $i^{\text {th }}$ experimental setup. The grey relational coefficient is expressed by using Equation (4)

$\xi_{i}(k)=\frac{\Delta_{\min }+\zeta \Delta_{\max }}{\Delta_{0 i}(k)+\zeta \Delta_{\max }}$

Where, $\Delta_{\min }$ is zero, $\Delta_{\max }$ is one; $\zeta$ is distinguishing coefficient is 0.5 and $\Delta_{\mathrm{oi}}(\mathrm{k})$ is the deviation sequence of the experiment trial.

\section{Analysis of Experimental Result}

\subsection{Optimal Parameters for Injection Moulding Process}

The experiment was based on Taguchi method that has total of 9 runs that consists of four factors and three levels as shown in Table 2. Three multiobjective optimization problems such as ultimate tensile strength (UTS), modulus and percentage of elongation (EL) has been transformed into a single objective optimization problem using the combination of Taguchi approach and grey relational analysis (GRA).
Table 2: Experimental layout and the responses

\begin{tabular}{|c|c|c|c|c|c|c|c|}
\hline Run & MoT & MeT & IT & CT & $\begin{array}{c}\text { UTS } \\
(\mathbf{M P a})\end{array}$ & $\begin{array}{c}\text { Modulus } \\
(\mathbf{M P a})\end{array}$ & $\begin{array}{c}\text { EL } \\
(\%)\end{array}$ \\
\hline 1 & 50 & 250 & 0.63 & 12.6 & 23.61 & 947.55 & 29.27 \\
\hline 2 & 50 & 280 & 0.7 & 14 & 23.46 & 953.39 & 35.26 \\
\hline 3 & 50 & 310 & 0.77 & 15.4 & 23.54 & 939.37 & 34.33 \\
\hline 4 & 56 & 250 & 0.7 & 15.4 & 24.73 & 981.76 & 31.37 \\
\hline 5 & 56 & 280 & 0.77 & 12.6 & 24.38 & 970.59 & 33.07 \\
\hline 6 & 56 & 310 & 0.63 & 14 & 24.41 & 949.58 & 32.65 \\
\hline 7 & 62 & 250 & 0.77 & 14 & 24.58 & 966.82 & 31.79 \\
\hline 8 & 62 & 280 & 0.63 & 15.4 & 24.78 & 1014.72 & 32.23 \\
\hline 9 & 62 & 310 & 0.7 & 12.6 & 24.43 & 958.28 & 31.91 \\
\hline
\end{tabular}

The original sequences of all responses were normalized based on Equation (1) which demand for "the-larger-the-better" characteristic for ultimate tensile strength, modulus and percentage of elongation. The result from normalization is shown in Table 3.

Table 3: The sequences of each performance characteristic after data preprocessing

\begin{tabular}{|c|c|c|c|}
\hline Run & $\begin{array}{c}\text { UTS } \\
(\mathbf{M P a})\end{array}$ & Modulus (MPa) & Elongation (\%) \\
\hline 1 & 0.1136 & 0.1086 & 0.0000 \\
\hline 2 & 0.0000 & 0.1861 & 1.0000 \\
\hline 3 & 0.0606 & 0.0000 & 0.8447 \\
\hline 4 & 0.9621 & 0.5626 & 0.3506 \\
\hline 5 & 0.6970 & 0.4143 & 0.6344 \\
\hline 6 & 0.7197 & 0.1355 & 0.5643 \\
\hline 7 & 0.8485 & 0.3643 & 0.4207 \\
\hline 8 & 1.0000 & 1.0000 & 0.4942 \\
\hline 9 & 0.7348 & 0.2510 & 0.4407 \\
\hline
\end{tabular}

The deviation sequences and the distinguishing coefficient then were substituted into Equation (4) to obtain the grey relational coefficients as well as its grade as presented in Table 4. From the table, it is observed that the experiment run no. 8 has the highest grey relational grade (GRG). Hence, the experiment no.8 gives the best multiple performance characteristics among the nine experiments. The higher value of grey relational grade shows a better characteristic of the multiple performances.

Table 4: The calculated grey relational coefficient for all comparability sequences and grey relational grade

\begin{tabular}{|c|c|c|c|c|}
\hline Run & $\begin{array}{c}\text { UTS } \\
(\mathbf{M P a})\end{array}$ & $\begin{array}{c}\text { Modulus } \\
(\mathbf{M P a})\end{array}$ & $\begin{array}{c}\text { Elongation } \\
(\boldsymbol{\%})\end{array}$ & $\begin{array}{c}\text { Grey } \\
\text { Relational } \\
\text { Grade }\end{array}$ \\
\hline 1 & 0.3607 & 0.3593 & 0.3333 & 0.3511 \\
\hline 2 & 0.3333 & 0.3805 & 1.0000 & 0.5713 \\
\hline 3 & 0.3474 & 0.3333 & 0.7631 & 0.4813 \\
\hline 4 & 0.9296 & 0.5334 & 0.4350 & 0.6327 \\
\hline 5 & 0.6226 & 0.4605 & 0.5776 & 0.5536 \\
\hline 6 & 0.6408 & 0.3664 & 0.5343 & 0.5139 \\
\hline 7 & 0.7674 & 0.4403 & 0.4633 & 0.5570 \\
\hline 8 & 1.0000 & 1.0000 & 0.4971 & 0.8324 \\
\hline 9 & 0.6535 & 0.4003 & 0.4720 & 0.5086 \\
\hline
\end{tabular}

The larger-the-better quality characteristic was used for analyzing the grey relational grade, since a larger value indicates the better performance of the process. Figure 1 shows factor response graph obtained from grey relational analysis. This result shows that the best processing condition is mould temperature of $62^{\circ} \mathrm{C}$, melt temperature of $280^{\circ} \mathrm{C}$, injection time of $0.70 \mathrm{~s}$ and cooling time $15.4 \mathrm{~s}$. By using this set of optimum parameters, the value of GRG is increased to 0.8375 which is higher than 0.8324 from experiment no. 8 . 


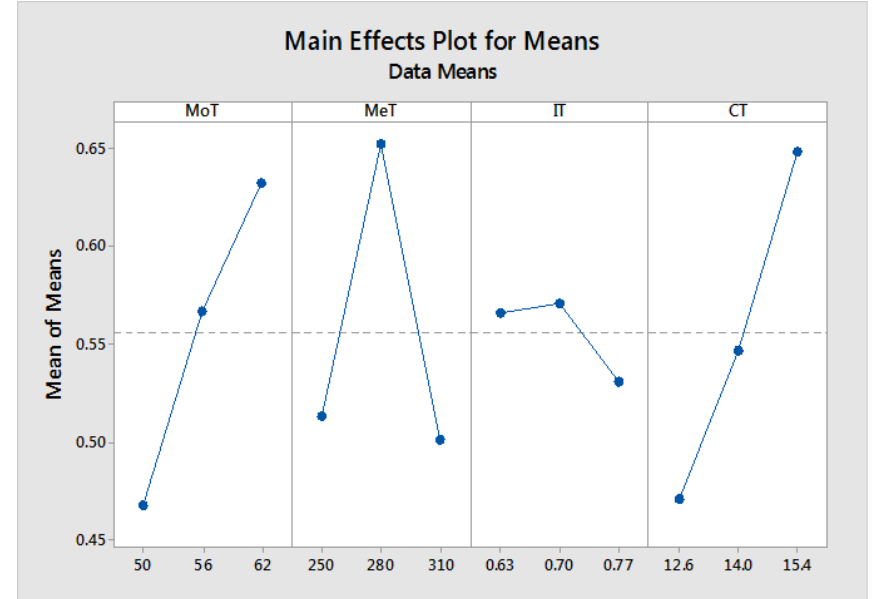

Figure 1: Factor response graph obtained from grey relational analysis

\subsection{Analysis of Variance (ANOVA)}

In order to investigate the significance of the injection moulding process parameters on the multiple performance characteristics, the analysis of variance (ANOVA) was conducted. The result from ANOVA is presented in Table 5. According to Table 5, it can be noticed that the highest contribution is cooling time, followed by mould temperature and melt temperature.

Table 5: ANOVA results

\begin{tabular}{|c|c|c|c|c|}
\hline Parameters & DOF & Sum of Squares & p-value & $\begin{array}{c}\text { Contribution } \\
\%\end{array}$ \\
\hline $\begin{array}{c}\text { Mold } \\
\text { Temperature }\end{array}$ & 2 & 0.04126 & 0.332 & 30.77 \\
\hline $\begin{array}{c}\text { Melt } \\
\text { Temperature }\end{array}$ & 2 & 0.04228 & 0.321 & 31.53 \\
\hline Injection Time & 2 & 0.002881 & 0.937 & 2.15 \\
\hline Cooling Time & 2 & 0.04768 & 0.268 & 35.56 \\
\hline Error & 0 & & & 100 \\
\hline Total & 8 & 0.13410 & & \\
\hline
\end{tabular}

\section{Conclusion}

The objective of this study is to optimize injection moulding parameters such as mould temperature, melt temperature, injection time and cooling time on mechanical properties of plastic part. It is found that the GRG increases by using optimum parameter setting about 0.6 per cent. Further, the result shows that mould temperature of $62^{\circ} \mathrm{C}$, melt temperature of $280^{\circ} \mathrm{C}$, injection time of $0.70 \mathrm{~s}$ and cooling time $15.4 \mathrm{~s}$ are optimum multi objective process setting. In addition, ANOVA result shows that the cooling time is the most influenced factor that affects the mechanical properties of plastic part followed by mould temperature and melt temperature. Therefore, this study indicates that Taguchi method with GRA approach can be implemented successfully to injection moulding process parameters optimization for multiobjective responses.

\section{Acknowledgement}

The authors would like to thank Faculty of Manufacturing Engineering, Universiti Teknikal Malaysia Melaka (UTeM) for providing facilities for this research to be conducted successfully. This research is funded by the Ministry of Higher Education through Research Acculturation Grant Scheme RAGS/1/2014/TK01/FKP/B00075.

\section{References}

[1] F. A. Ghasemi, I. Ghasemi, S. Menbari, M. Ayaz, and A. Ashori, "Optimization of mechanical properties of polypropylene/talc/graphene composites using response surface methodology," Polym. Test., vol. 53, pp. 283-292, 2016.

[2] N. I. Zulkifli, N. Samat, H. Anuar, and N. Zainuddin, "Mechanical properties and failure modes of recycled polypropylene/microcrystalline cellulose composites," Mater. Des. vol. 69, pp. 114-123, 2015.

[3] M. Amran, R. Izamshah, M. Hadzley, M. Shahir, M. Amri, M. Sanusi, and H. Hilmi, "The Effect of Binder on Mechanical Properties of Kenaf Fibre/Polypropylene Composites using Full Factorial Method.” App. Mech. and Mat., vol. 695, pp. 709-712, 2015.

[4] E. Kuram, E. Tasci, A. Ihsan, M. Metin, F. Yilmaz, and B. Ozcelik, "Investigating the effects of recycling number and injection parameters on the mechanical properties of glass-fibre reinforced nylon 6 using Taguchi method," Mater. Des., vol. 49, pp. 139-150, 2013.

[5] S. E. Mirvar, R. M. Kaleybar, and A. Afsari, "Optimization of injection molding process parameters to increase the tensile strength in polyamide-specimen using the taguchi method," Adv. Mater. Res., vol. 341-342, pp. 395-399, 2011.

[6] N. M. Mehat, S. Kamaruddin, and A. R. Othman, "Investigating the Effects of Injection Moulding Process Parameters on Multiple Tensile Characteristics of Plastic Spur Gear via Experimental Approach," Adv. Mater. Res., vol. 748, pp. 544-548, 2013.

[7] M. Amran, S. Salmah, A. Faiz, R., Izamshah, M. Hadzley, B. Manshoor, M. Shahir, and M., Amri, "Effect of Injection Moulding Machine Parameters on the Warpage by Applying Taguchi Method." App. Mech. and Mat. vol. 699, pp. 20-25, 2015.

[8] M. A. Amran, M. Hadzley, S. Amri, R. Izamshah, A. Hassan, S. Samsi and K. Shahir, "Optimization of gate, runner and sprue in two-plate family plastic injection mould." in AIP Proc., 2010, vol. 1217, no. 1, pp. 309-313.

[9] D. Kusić, T. Kek, J. M. Slabe, R. Svečko, and J. Grum, "The impact of process parameters on test specimen deviations and their correlation with AE signals captured during the injection moulding cycle," Polym. Test., vol. 32, pp. 583-593, 2013.

[10] M. A. Md Ali, N. Idayu, M. S. Abd Aziz, M. Hadzley, and Sivaraos, "Optimisation of process parameters in linear runner family injection mold using moldflow simulation software," ARPN J. Eng. Appl. Sci., vol. 11, no. 4, pp. 2475-2482, 2016.

[11] H. Pervez, M. Mozumder, and A.-H. Mourad, "Optimization of Injection Molding Parameters for HDPE/TiO2 Nanocomposites Fabrication with Multiple Performance Characteristics Using the Taguchi Method and Grey Relational Analysis," Mat. (Basel)., vol. 9, no. 8, p. 710, 2016

[12] S. Gobinath, D. Elangovan, E. Sivakumar, and S. R. Devadasan, "Viability study of use of reprocessed high density polyethylene for manufacturing products and multi response optimization of injection moulding parameters using grey relational analysis," Polym. Polym. Compos., vol. 24, no. 7, pp. 547-555, 2016.

[13] B. Mathew, Benkim, and J. Babu, "Multiple process parameter optimization of WEDM on AISI304 using utility approach," Procedia Mater. Sci., vol. 5, pp. 1863-1872, 2014.

[14] M. A. M. Amran, N. Idayu, K. M. Faizal, M. Sanusi, R. Izamshah, and M. Shahir, "Part weight verification between simulation and experiment of plastic part in injection moulding process," in IOP Conf. Series: Mat. Sci. and Eng., 2016, vol. 160, pp. 1-7.

[15] D. Bhattacharya and B. Bepari, "Feasibility study of recycled polypropylene through multi response optimization of injection moulding parameters using grey relational analysis," Procedia Eng., vol. 97, pp. 186-196, 2014. 